Revista de Investigación Educativa 26

enero-junio, 2018 | ISSN 1870-5308 | Xalapa, Veracruz

Instituto de Investigaciones en Educación | Universidad Veracruzana

\title{
Renovación, oportunidad y regulación editorial
}

Miguel Figueroa Saavedra Ruiz

$\mathrm{L}$ a CPU-e, Revista de Investigación Educativa cierra con este número una etapa que no implica un término, sino una adecuación a las nuevas necesidades. En los últimos cuatro años esta revista ha tratado de consolidar su calidad a partir del cumplimiento de ciertos indicadores y procedimientos, teniendo como logro destacado su inclusión en el índice SCIELO, como ya anunciamos en el anterior número.

Sin embargo, aún hay que superar problemas que siguen alterando el regular ritmo de las publicaciones periódicas. A este respecto, la CPU-e es una revista que ha conseguido mantener su periodicidad a pesar de los consabidos problemas que aquejan hoy a las revistas académicas (falta de calidad o pertinencia de algunas colaboraciones enviadas, retrasos en los procesos de dictamen, sobrecarga de trabajo editorial).

De igual manera, ha logrado una proporción adecuada de colaboraciones, buscando una composición de $80 \%$ de artículos de investigación, 10\% de artículos de práctica y $10 \%$ de reseñas. Con esta fórmula se procura ofrecer contenidos que contribuyan a estimular y dinamizar el campo de los estudios sobre la educación y generar un espacio de oportunidad para la difusión y discusión del conocimiento

a Doctor. Investigador Titular. Director de la CPU-e, Revista de Investigación Educativa. Instituto de Investigaciones en Educación, Universidad Veracruzana, México.凶 migfigsaa@yahoo.com.mx 
generado. Así también, nos satisface advertir que la CPU-e sirve de plataforma para el conocimiento de investigaciones desarrolladas en diferentes continentes, con estudios realizados en países como Angola, Brasil, Colombia, España, Finlandia, Francia, México y Venezuela. De tal suerte que la revista ha ido abriendo su panorama inicial, localizado en el ámbito estatal y nacional y en la educación superior, hacia un panorama internacional, euro-latinoamericano, y con contribuciones sobre todos los niveles de la educación formal y la educación especial, además de aportaciones en el campo teórico y metodológico. Esta amplitud y diversidad, a pesar de su carácter especializado, responde en gran medida al haber podido contar con expertos en diversas temáticas dispuestos a ser parte de nuestra cartera de dictaminadores, y de un comité editorial interno y externo capaz de orientar el proceso de dictaminación y edición.

Hoy muchos de estos logros y procedimientos se verán reafirmados con la adecuación de nuestro marco normativo a la propia reforma del Reglamento Editorial de la Universidad Veracruzana (Uv). Esta renovación responde a seguir impulsando la prestigiosa tradición editorial de la uv y el valor que dentro del campo de la generación y socialización del conocimiento representa su sello editorial. La CPU-e, como producto editorial de esta casa de estudios, consciente de lo que representa este respaldo institucional y su contribución al mantenimiento de la calidad de esta oferta científica, se ha sumado a dicha renovación apegando su organigrama y procedimientos editoriales a los criterios de calidad del Consejo Editorial de la UV y su política editorial institucional.

Por esta razón, el Instituto de Investigaciones en Educación se dota de un nuevo Comité Editorial que pasa a coordinar, agilizar y supervisar la labor editorial de la CPU-e y de la Biblioteca Digital de Investigación Educativa, y su propio Comité Editorial, en colaboración con la Dirección Editorial de la Uv. Por esta vía, la CPU-e seguirá enriqueciendo el acervo de publicaciones digitales del Catálogo de Revistas de la Uv.

Es de esperar que con todo el bagaje y experiencia ya acumulados por un competente y cualificado equipo editorial, por el respaldo de nuestros colaboradores y lectores, por el reconocimiento editorial e institucional, estos cambios ayudarán a ir enriqueciendo, diversificando y adecuando a las necesidades sociales y académicas emergentes nuestros contenidos, y a asegurar a los investigadores el disponer de una plataforma de difusión del conocimiento óptima ante las urgencias y ritmos de publicación que hoy día se imponen, sin perder con ello la calidad que garantiza un adecuado proceso de selección y dictamen. - 